\title{
A map of radon flux at the Australian land surface
}

\author{
A. D. Griffiths, W. Zahorowski, A. Element, and S. Werczynski \\ Australian Nuclear Science and Technology Organisation, Locked Bag 2001, Kirrawee DC, NSW, 2232, Australia
}

Received: 27 April 2010 - Published in Atmos. Chem. Phys. Discuss.: 9 June 2010

Revised: 9 September 2010 - Accepted: 10 September 2010 - Published: 27 September 2010

\begin{abstract}
A time-dependent map of radon-222 flux density at the Australian land surface has been constructed with a spatial resolution of $0.05^{\circ}$ and temporal resolution of one month. Radon flux density was calculated from a simple model utilising data from national gamma-ray aerial surveys; modelled soil moisture, available from 1900 in near realtime; and maps of soil properties. The model was calibrated against a data set of accumulation chamber measurements, thereby constraining it with experimental data. A notable application of the map is in atmospheric mixing and transport studies which use radon as a tracer, where it is a clear improvement on the common assumption of uniform radon flux density.
\end{abstract}

\section{Introduction}

Radon-222, or radon, is a radioactive noble gas which is exhaled by soil and rock to the atmosphere. Radioactive decay is the only significant removal process, so it is an ideal tracer for studying physical processes with a timescale comparable to its 3.8 day half-life.

Radon-222 is a member of the uranium-238 decay series and its immediate parent is radium-226, with a half-life of 1600 years. Radon-222 decays to polonium-218 (half-life of $3.1 \mathrm{~min}$ ) followed by lead-214 (half-life of $27 \mathrm{~min}$ ) and then to bismuth-214. Bismuth-214 is the first element in the series which emits gamma rays that can be detected in aerial surveys and, by assuming secular equilibrium, data from these surveys can be used to map the topsoil concentration of radioelements in the uranium-238 decay series (Minty, 1997).

Radon-220, or thoron, is a less abundant radon isotope and a member of the thorium-232 decay series. With a half-life

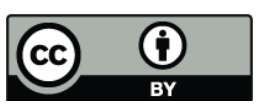

Correspondence to: A. D. Griffiths (alan.griffiths@ansto.gov.au) of $56 \mathrm{~s}$, it is suited for studying vertical mixing in the atmospheric surface layer (Lehmann et al., 1999). A gamma emitter in the thorium decay series, thallium-208, can be used to map the concentration of radioisotopes in the thorium series, so the methods used to map radon-222 fluxes can be similarly applied to radon-220. In this paper, however, we consider radon-220 only as an aid in interpreting our results.

Globally the land surface is the dominant source of radon, as the flux density at the ocean surface is around two orders of magnitude smaller (Schery and Huang, 2004). Although commonly assumed to be constant, the land-surface flux of radon varies in space and time. The constant-flux assumption is convenient because the global mean radon flux density has been well known for some time (e.g. Jacob et al., 1997) whereas variations on smaller scales are not well characterised.

Uncertainty in flux density limits the usefulness of radon in atmospheric studies, where it has found numerous applications. These include using radon to test mixing and transport processes in atmospheric models (Gupta et al., 2004; Jacob et al., 1997; Zhang et al., 2008) and for calibrating regional flux estimates of greenhouse gases (Hirsch, 2007; Biraud et al., 2000). These applications, and others, are reviewed by Zahorowski et al. (2004).

Motivated by improving these types of studies, several groups have progressed towards better characterisation of regional radon flux density. For the northern hemisphere, Conen and Robertson (2002) suggest a radon flux of $21.0 \mathrm{mBq} \mathrm{m}^{-2} \mathrm{~s}^{-1}\left(1\right.$ atom $\left.\mathrm{cm}^{-2} \mathrm{~s}^{-1}\right)$ over ice-free land areas south of $30^{\circ} \mathrm{N}$ and a linear decrease northwards to reach $4.2 \mathrm{mBq} \mathrm{m}^{-2} \mathrm{~s}^{-1}\left(0.2\right.$ atom $\left.\mathrm{cm}^{-2} \mathrm{~s}^{-1}\right)$ at $70^{\circ} \mathrm{N}$. A similar meridional flux density gradient was reported by Williams et al. (2009), based on atmospheric measurements in East Asia.

A more detailed picture, which includes spatial and temporal variability and yet remains consistent with Conen and Robertson's estimate, has been produced for Europe using

Published by Copernicus Publications on behalf of the European Geosciences Union. 
terrestrial gamma dose rate as a proxy (Szegvary et al., 2007, 2009). As well as spatial variability, parts of Europe have a strong seasonal cycle, with weekly average fluxes between $65^{\circ} \mathrm{N}$ and $70^{\circ} \mathrm{N} 2.5$ times larger in summer than winter. By contrast, the seasonal cycle south of $50^{\circ} \mathrm{N}$ is much weaker.

For China, a similar map was reported by Zhuo et al. (2008) who used maps of soil properties and climate information to estimate fluxes. They avoided using gamma dose rate as an input parameter because it is not a function of radium content alone. Averaged across China, the flux density is 1.75 times larger in summer than winter.

Seasonal variation in radon fluxes, which is present in flux maps of both China and Europe, are largely attributable to the effect of the seasonal cycle of soil moisture. Wet soil reduces the flux of radon at the surface by reducing the diffusion rate of radon through the soil matrix (Nazaroff, 1992; Papachristodoulou et al., 2007; Rogers and Nielson, 1991). The seasonal cycle of soil temperature can also introduce a seasonal radon cycle because diffusion becomes more vigorous at higher temperatures (Schery and Wasiolek, 1998).

As well as the aforementioned regional maps, global maps of radon flux density have been compiled. Their authors point to the maps' preliminary nature (Schery and Wasiolek, 1998) or to the need for better input data (Goto et al., 2008), so the Australian region remains without detailed coverage. The aim of the present work is to improve this situation by developing a map of radon-222 surface flux density, covering Australia with a spatial resolution of $0.05^{\circ}$ and temporal resolution of one month.

\section{Methods}

In general terms, our approach is to use point measurements of radon flux density to calibrate a simple diffusive transport model and then use the model to generate a map.

We restrict ourselves to a simple model, even though more sophisticated models are required to better reproduce dayto-day variations in radon flux (Holford et al., 1993). This is because input parameters are available to drive a simple model at regional scale and because, over time periods of about ten days or longer, the mean flux density is close to that calculated from diffusion (Schery et al., 1984). Neglecting short-term variability, though, means that instantaneous fluxes may differ from modelled fluxes by around a factor of two (Holford et al., 1993).

\subsection{Accumulation chamber measurements}

The accumulation chamber measurements available for model calibration are listed in Table 1.

At each measurement site, an accumulation chamber was placed on the ground and soil from nearby was quickly piled around the edge of the chamber to seal it. For a 24 min period, air was drawn from the chamber into two scintillation cells, separated by a six-minute delay line, and then recycled back into the chamber. Fluxes of both radon-222 and radon220 are measured using this approach. Details of the instrument design and data analysis are given in Zahorowski and Whittlestone (1996); for a radon-222 flux of $4 \mathrm{mBq} \mathrm{m}^{-2} \mathrm{~s}^{-1}$ the counting error is $30 \%$.

This instrument was used to collect all of the data listed in Table 1 with the exception of the mainland survey which used a different device, but following the same principle (Schery et al., 1989). In a comparison with eight others at a field site, the radon flux density measured with our instrument was within one standard deviation of the mean and higher by 31\% (Hutter and Knutson, 1998). More recently, however, the instrument was found to be within $5 \%$ of the accumulation chamber used by Szegvary et al. (2007) in a laboratory comparison (Werczynski et al., 2010).

The presence of an accumulation chamber reduces the rate at which radon diffuses out of soil, thus introducing a systematic error. Mayya (2004) analysed this effect in a twodimensional framework and, based on this analysis, our accumulation chamber measurements are expected to be low by about $10 \%$, for a 24 min counting period and assuming typical values of soil porosity $(\epsilon=0.4)$ and radon diffusion length $\left(l_{d}=1 \mathrm{~m}\right)$ (Mayya, 2004, Eq. 26b). A detailed correction for this effect requires knowledge of soil parameters at each measurement site and assumes an idealised accumulation chamber configuration that is not typically realised in the field. As a result, we have chosen to present the flux measurements without this correction and simply note the possibility of a systematic error of around $10 \%$ in the final result.

\subsection{Diffusion model}

The transport of radon from soil to air is reviewed by Nazaroff (1992) and here we discuss the simplified representation of the process implemented in our model.

Radon-222 is produced within soil grains at a rate equal to the specific activity of its parent, radium-226. A fraction of the generated radon enters the pore space; this is called the emanation fraction, $f$, with a representative range of 0.10.4 (Markkanen and Arvela, 1992). The emanation fraction for a dry soil is a factor of 2-3 lower than for soil at around $10 \%$ of saturation (Zhuo et al., 2006) because soil grains in moist soil are enveloped by a water film which decelerates recoiling nuclei that would otherwise travel across the pore space to become embedded in adjacent soil grains (Sasaki et al., 2004; Sakoda et al., 2010). Increasing soil moisture beyond $10 \%$ has little further impact on $f$.

Radon in the air-filled pore space diffuses down the concentration gradient towards the surface. It also diffuses through water, but we neglect this effect as the diffusion coefficient in water is about five orders of magnitude smaller than in air. For one-dimensional diffusion, the bulk flux density, $J$, can be expressed with Fick's law as 
Table 1. Accumulation chamber measurements of radon flux density ordered by mean flux density.

\begin{tabular}{|c|c|c|c|c|c|c|}
\hline Location & Date & Location centre & $\begin{array}{c}\text { Radius } \\
\text { km }\end{array}$ & $\mathrm{N}^{\mathrm{a}}$ & $\begin{array}{c}\text { Mean flux density } \\
\mathrm{mBqm}^{-2} \mathrm{~s}^{-1}\end{array}$ & $\begin{array}{c}\text { Mean } A_{\mathrm{Ra}}{ }^{\mathrm{Bq} \mathrm{kg}} \\
\mathrm{Bg} \mathrm{k}^{-1}\end{array}$ \\
\hline Cataract & 1998 & $34.2^{\circ} \mathrm{S}, 150.7^{\circ} \mathrm{E}$ & 0.2 & 175 & 12.8 & 16.6 \\
\hline Tasmania survey $^{\mathrm{c}}$ & Feb, Aug 1996; Dec 1997 & $42.2^{\circ} \mathrm{S}, 146.6^{\circ} \mathrm{E}$ & 150 & 20 & 17.3 & 18.2 \\
\hline Goulburn & Aug 2006 & $34.8^{\circ} \mathrm{S}, 149.7^{\circ} \mathrm{E}$ & 20 & 33 & 18.1 & 17.7 \\
\hline Mainland survey ${ }^{\mathrm{d}}$ & Jun 1986 & $25^{\circ} \mathrm{S}, 132^{\circ} \mathrm{E}$ & 1800 & 61 & 27.5 & 18.3 \\
\hline Goulburn & Feb 2008 & $34.8^{\circ} \mathrm{S}, 149.7^{\circ} \mathrm{E}$ & 20 & 18 & 51.3 & 19.4 \\
\hline Mary River & Sep 2008 & $12.8^{\circ} \mathrm{S}, 131.6^{\circ} \mathrm{E}$ & 26 & 35 & 185 & 99.2 \\
\hline Cowra & Feb 2008 & $33.9^{\circ} \mathrm{S}, 148.5^{\circ} \mathrm{E}$ & 5 & 24 & 229 & 82.4 \\
\hline Cowra & Jul 2008 & $33.9^{\circ} \mathrm{S}, 148.5^{\circ} \mathrm{E}$ & 5 & 23 & 264 & 84.1 \\
\hline
\end{tabular}

a Number of points in data set that passed quality control and with radium data available.

b Equivalent radium specific activity in topsoil, $A_{\mathrm{Ra}}$, from radiometrics. For Cowra and Mary River these were point measurements made using a hand-held gamma spectrometer, for the Tasmmanian survey these were determined from soil samples analysed with a germanium gamma detector and then adjusted to match aerial survey data on average. Other data are taken from airborne measurements (Minty et al., 2009).

${ }^{c}$ From Whittlestone et al. (1998) (February, August 1996) and Zahorowski and Lautenschläger (unpublished data)(December 1997).

d From Schery et al. (1989).

$J=-\epsilon D_{e} \frac{\partial C}{\partial z}$

where $\epsilon$ is the soil porosity, $D_{e}$ is the effective diffusion coefficient in the porous medium, $C$ is the radon activity concentration in the pore air, and $z$ is distance. As conventions vary, we emphasise that here $J$ is the flux density per unit bulk area whereas $C$ is the concentration of radon per unit pore volume. The transport equation for pore-gas radon concentration is derived using (1) assuming conservation of radon, assuming that $\epsilon$ and $D_{e}$ are constants, and including sink and source terms. After these steps

$$
\frac{\partial C}{\partial t}=D_{e} \frac{\partial^{2} C}{\partial z^{2}}-\lambda C+\frac{\lambda \rho_{b} A_{\mathrm{Ra}} f}{\epsilon}
$$

where $t$ is time, $\lambda \simeq 2.1 \times 10^{-6} \mathrm{~s}^{-1}$ is the radon-222 decay constant, $A_{\mathrm{Ra}}$ is the specific activity of radium-226 (units of activity per mass of dry soil) $\rho_{b}$ is the dry soil bulk density, and $f$ is the emanation fraction.

To solve Eq. (2) we assume: steady-state; the existence of a soil layer of infinite thickness with soil-air interface at $z=0$; a coordinate system with positive $z$ downwards; and boundary conditions $C(0)=0$ and finite $C(\infty)$. Provided we are not concerned with the value of $C$ near the soil surface, choosing $C(0)=0$ is generally a good approximation as atmospheric radon concentrations are typically three orders of magnitude smaller than in the soil gas at depth. With these boundary conditions

$C=C_{\infty}\left[1-\exp \left(-z / l_{d}\right)\right]$

where $C_{\infty}=\rho_{b} A_{\mathrm{Ra}} f / \epsilon$ is the asymptotic radon concentration at depth and $l_{d}=\sqrt{D_{e} / \lambda}$ is called the diffusion length, the characteristic length that radon atoms diffuse before decaying. By evaluating $\partial C / \partial z$ at $z=0$ and substituting into Eq. (1) we find that the flux density at the surface is

$J(0)=-\rho_{b} A_{\mathrm{Ra}} f \sqrt{\lambda D_{e}}$,

which is negative signifying radon transport from soil to air.

Empirical relationships are used to define $f$ and $D_{e}$. Following Zhuo et al. (2008), the emanation fraction is

$f=f_{0}\{1+a[1-\exp (-b m)]\}[1+c(T-298)]$

where $f_{0}, a, b$ and $c$ are parameters (shown in Table 2) that depend on soil texture, $m$ is soil moisture expressed as fraction of saturation, and $T$ is soil temperature in kelvin. By defining soil to be a mixture of clay, silt and sand, we compute $f$ as a weighted sum according to the fraction of each texture class.

The effective diffusion coefficient, $D_{e}$, is defined according to an observed correlation with soil moisture (Rogers and Nielson, 1991),

$D_{e}=D_{a 0} \epsilon \exp \left(-6 m \epsilon-6 m^{14 \epsilon}\right)$

where $D_{a 0}=1.1 \times 10^{-5}(T / 273)^{3 / 2} \mathrm{~m}^{2} \mathrm{~s}^{-1}$ is the diffusion coefficient for radon in air which includes a dependence on temperature, equal to the soil temperature in this case (Schery and Wasiolek, 1998), $m$ is moisture saturation with $0 \leq m \leq 1$, and $\epsilon$ is porosity.

Both $f$ and $D_{e}$ are functions of moisture, so flux density at the soil surface is a nonlinear function of moisture with a maximum around $m=0.1$ (Fig. 1).

With the definition of the diffusion length, $l_{d}=\sqrt{D_{e} / \lambda}$, we can relax the need for an infinitely thick soil layer, and instead require a layer of thickness $d \gg l_{d}$. For radon-222, $l_{d} \sim 1 \mathrm{~m}$ is typical so $d \gg l_{d}$ is not necessarily realised in practise. 
Table 2. Emanation parameters from Zhuo et al. (2008) and grain size definitions from United States Department of Agriculture (2002). A misprint in the original table of emanation parameters has been corrected.

\begin{tabular}{lrrrrr}
\hline Soil texture & Grain Size $(\mathrm{mm})$ & $f_{0}$ & $a$ & $b$ & $c$ \\
\hline Clay & $<0.002$ & 0.18 & 1.53 & 21.8 & 0.011 \\
Silt & $0.002-0.5$ & 0.14 & 1.73 & 20.5 & 0.010 \\
Sand & $0.5-2$ & 0.10 & 1.85 & 18.8 & 0.012 \\
\hline
\end{tabular}

Contradicting the discussion so far, soil properties typically vary with depth. In order to account for this, the model can be extended by defining multiple layers of homogeneous soil. Our input data are defined for two layers only, so we define two soil layers where layer 1 extends from the surface to an arbitrary depth $d_{1}$, and layer 2 extends from $d_{1}$ down to $d_{2}=\infty$, though physically we take this to mean that $d_{2}-d_{1} \gg l_{d}$. The introduction of a second soil layer has been shown to significantly improve the match between modelled and observed radon profiles in soil (AntonopoulosDomis et al., 2009).

Soil properties, including moisture, are constant within the two layers but are permitted to take different values in each layer and are assigned the subscript 1 or 2 to indicate which layer they apply to. As before, $C(0)=0$ and $C(\infty)$ is finite. In addition, $C$ and $J$ are continuous at $d_{1}$, the depth of the interface between the layers. The steady state solution can be expressed analytically; at the soil surface, the flux density is

$$
J(0)=\frac{\left\{\begin{array}{l}
{\left[2 f_{1} B \sqrt{D_{e 1}}\right] J_{02}+} \\
{\left[f_{2}(B-1)^{2} \sqrt{D_{e 2}}+f_{1}\left(1-B^{2}\right) \sqrt{D_{e 1}}\right] J_{01}}
\end{array}\right\}}{f_{2}\left(1-B^{2}\right) \sqrt{D_{e 2}}+f_{1}\left(B^{2}+1\right) \sqrt{D_{e 1}}}
$$

where

$$
\begin{aligned}
J_{01} & =-\rho_{1} A_{\mathrm{Ra} 1} f_{1} \sqrt{\lambda D_{e 1}} \\
J_{02} & =-\rho_{2} A_{\mathrm{Ra} 2} f_{2} \sqrt{\lambda D_{e 2}} \\
B & =\exp \left(-d_{1} \sqrt{\lambda / D_{e 1}}\right)=\exp \left(-d_{1} / l_{d 1}\right)
\end{aligned}
$$

The terms $J_{01}$ and $J_{02}$ are surface fluxes that would be observed for homogeneous soil with the properties of layer 1 or 2, whereas $B$ depends on the ratio of the interface depth to the diffusion length in the top layer.

Despite the introduction of a second soil layer, Eq. (7) remains a highly idealised expression for a relatively complex process. Compounding this is that the quality of the best input data is lacking and that there is an almost total absence of estimates of uncertainties. The input data variously contain biases, are derived from model output, or are derived from empirical correlations. In order to constrain the map to

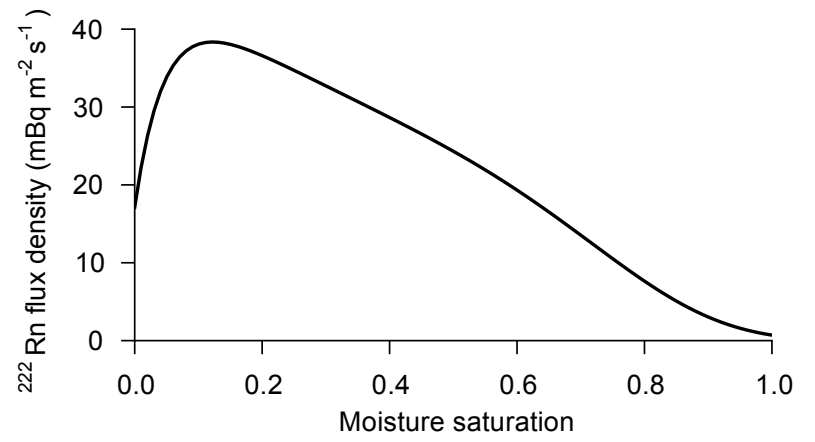

Fig. 1. Diffusive radon transport to the atmosphere versus soil moisture for a sandy loam ( $15 \%$ clay, $15 \%$ silt, $70 \%$ sand) according to Eq. (4), (5) and (6) with $A_{\mathrm{Ra}}=30 \mathrm{~Bq} \mathrm{~kg}^{-1}, \rho_{b}=1060 \mathrm{~kg} \mathrm{~m}^{-3}$, $\epsilon=0.4$, and $T=298 \mathrm{~K}$. At $m \simeq 0.03$ and $m \simeq 0.40$ the surface flux is $25 \%$ below its peak value.

match observed radon fluxes, we introduce an overall calibration factor defined such that the calibrated flux, $J_{c}$, is

$J_{c}=c J$

where $c$ is the calibration factor, which is assumed to be constant. Flux chamber measurements were used to find $c$ by minimising the difference between $J_{c}$ and measured fluxes in $\log$ space. This is equivalent to finding $c$ such that

$c=\left(\prod_{i=1}^{N} \frac{J_{i}}{J_{i}^{\prime}}\right)^{\frac{1}{N}}$

where $J_{i}$ is the measured flux at the $i$ th measurement location and $J_{i}^{\prime}$ is the uncalibrated modelled flux at the $i$ th measurement location.

By minimising the difference in log space, the computed value of $c$ is sensitive to data from locations with both large and small flux density, which is desirable as large radon fluxes are not distributed evenly throughout the measurement set. In our specific case, calculating $c$ in linear space yields a similar numerical value, but in this case $c$ is insensitive to fluxes from data sets other than the two with the highest flux measurements.

In effect, by introducing $c$, we modify the model so that it matches observations on average. A logical extension of this approach would be to make other modifications which would force other features of the model output to match observations; for example the model could be adjusted in order to match the observed seasonal cycle. We briefly investigated further modifications to the model, but were unable to improve its match with observations perhaps as a result of either having insufficient data to constrain model modifications or due to errors in model inputs. Similarly, there are too few observations to allow $c$ to be time-dependent or spatially-variable. 


\subsection{Model input data}

The input data for the radon flux model, Eq. (7), are taken from several sources. Other than radium activity, the (assumed) time-independent soil properties required to evaluate Eq. (7) are: bulk density, $\rho_{b}$, porosity, $\epsilon$, and soil texture expressed as the fraction of clay, silt and sand. These inputs originate from interpretations of the Atlas of Australian Soils (Northcote et al., 1960; McKenzie and Hook, 1992; McKenzie et al., 2000), which we obtained in digital form from the Australian Water Availability Project (AWAP: Raupach et al., 2008, 2009) and the Australian Natural Resources Data Library website (Bureau of Rural Sciences, 2009).

Radium data are taken from the Radiometric Map of Australia (Radmap 2009: Minty et al., 2009). Radmap 2009 is a mosaic of individual gamma ray aerial surveys (Minty, 2000), mostly with flight-line spacing of $500 \mathrm{~m}$ or less. It is back-calibrated to a coarse grid, flown in MarchDecember 2007, covering the country with flight line spacing of $75 \mathrm{~km}$ and which is itself back-calibrated to the International Atomic Energy Agency global datum.

Radmap coverage is close to $90 \%$ of the land mass, as shown in Fig. 2. To obtain a complete map, soil radium in areas without coverage was estimated by natural neighbour interpolation (Watson, 1999) to arrive at the distribution shown in Fig. 3. Although the gamma-ray signal comes from roughly the top $20 \mathrm{~cm}$ of soil, we assume that soil radium content is invariant with depth.

Topsoil and subsoil moisture, and air temperature, are taken from the AWAP model. Soil moisture is an important factor controlling flux density and is the most influential time-varying model input. As the diffusion length of radon222 is large enough for the surface flux to be influenced by subsoil moisture, the inclusion of subsoil moisture should improve radon flux estimates.

The AWAP model simulates soil moisture in a topsoil and subsoil layer with thicknesses defined from the Atlas of Australian Soils. The mean topsoil thickness is $23 \mathrm{~cm}$ and the mean subsoil thickness is $59 \mathrm{~cm}$. To calculate flux density, soil below the subsoil layer is assumed to have the same properties as the subsoil.

Air temperature is used as a proxy for soil temperature, which is an acceptable approximation due to the secondary importance of temperature to moisture. We use the midpoint of the monthly air temperature maxima and minima taken from the meteorological data set used to drive the AWAP model (Jones et al., 2007).

Both temperature and moisture are available as monthly fields from 1900 until present, and are currently being updated in near real time. The quality of these data improve with time, due to improvements in the meteorological observation network, so we focus on the period July 1979-June 2010 (inclusive) for the computation of long-term averages.

Radon flux density is calculated on the same grid as soil moisture, which is the lowest resolution input. This is a $0.05^{\circ}$
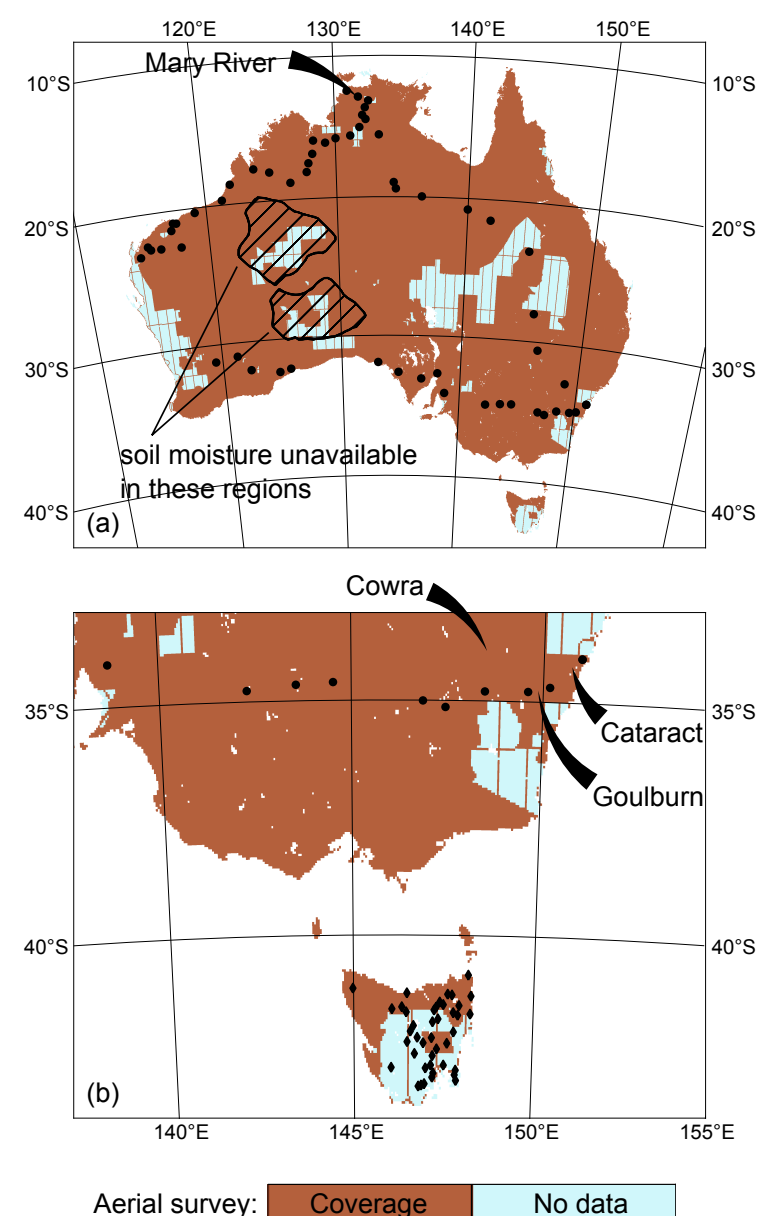

Fig. 2. Spatial coverage of input data: aerial gamma-ray survey, soil moisture and radon flux density. For the Mainland and Tasmanian flux density data the individual sample locations are plotted (as dots and diamonds respectively) and the other flux measurement locations are labelled.

grid, which equates to approximately $5 \times 5 \mathrm{~km}$ grid squares. Although we focus mainly on monthly data, weekly data is also available from 2007 onwards. The weekly data are used, when available, for calibrating the map, although doing so makes no significant difference to the result when compared with using only monthly fields. The availability of weekly data also opens the possibility of computing weekly radon flux maps, should the need arise.

Although all input data have uncharacterised uncertainties, we note that bulk density, porosity, and texture are taken from empirical correlations which have been observed between mapped soil types and soil physical properties (McKenzie and Hook, 1992; McKenzie et al., 2000). As these properties have been arrived at indirectly, there is considerable uncertainty in their derivation and they are, according to McKenzie et al. (2000), an "interim measure" prior to better estimates becoming available. As a result, the spatial variation in flux density that arises from changes in soil properties is expected 


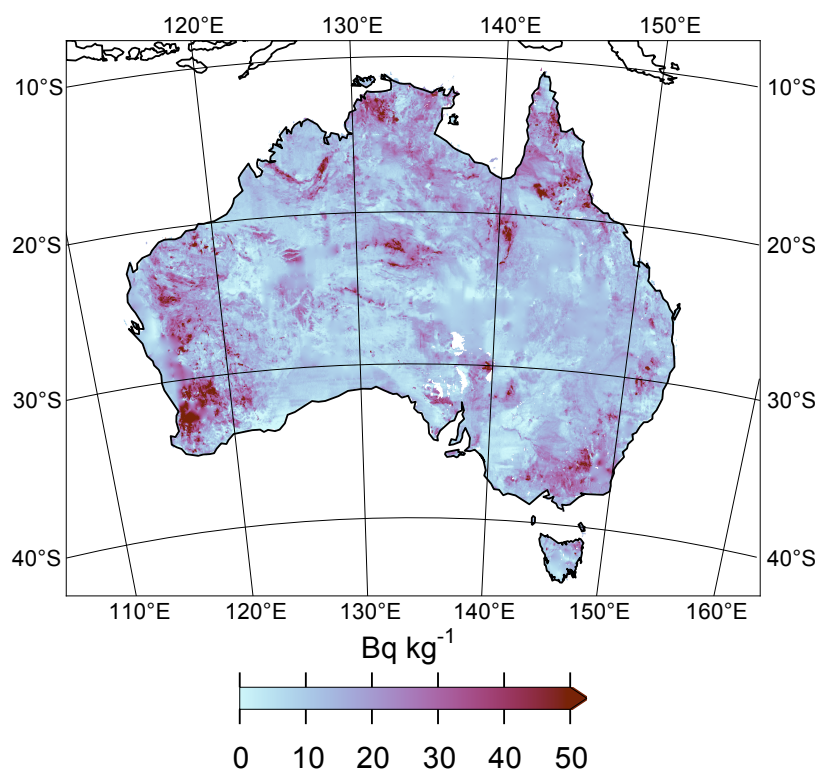

Fig. 3. Equivalent radium-226 specific activity in topsoil with gaps in the data filled by interpolation.

to be poorly depicted in the model compared with the effect of soil moisture and radium distribution.

\section{Results}

\subsection{Accumulation chamber measurements}

The results from accumulation chamber measurements are summarised in Table 1. The results are grouped into data sets by measurement campaign: the Tasmania and Mainland data sets are large-area surveys acquired over several weeks each; the Cowra, Mary River and Goulburn surveys cover small areas of less than $40 \mathrm{~km}$ across and were acquired over a week or so; and the Cataract coverage area was smaller still, with $400 \mathrm{~m}$ between the furthest points, but with repeat measurement made over a year. Each measurement is effectively a point measurement, acquired during 24 min over a surface area of $0.255 \mathrm{~m}^{2}$.

In order to sample a wide range of soil radium values, the Goulburn, Cowra, and Mary River surveys were made in regions with soil radium content ranging from typical to high values; this is reflected in the larger flux density measured at the locations with high radium. Repeat measurements were made in summer and winter, for the Goulburn, Cowra and Tasmanian data, in order to obtain information about temporal variation, although no effort was made to make measurements during particularly dry or wet periods.

\subsection{Radiometrics versus fluxes}

Previous studies have found a correlation between radon flux density and terrestrial gamma dose rate (Schery et al., 1989; Szegvary et al., 2007). A strong correlation may therefore also be expected between flux density and the gamma ray activity arising only from bismuth-214, a decay product of radon-222.

To test this hypothesis, radiometric measurements were made at flux measurement points during the Cowra and Mary River surveys, using an Exploranium GR-320 gamma spectrometer at the former and a Radiation Solutions RS-230 gamma spectrometer at the latter. These instruments rely on the same measurement principle as aerial surveys, but can be co-located with the flux measurement. Soil radium can vary significantly over the space of ten metres or less, so colocating the measurements maximises the chance of observing a correlation between gamma intensity and radon flux density. This comparison is shown in Fig. 4 for the two areas. Both data sets show higher radon flux density at sites which, based on bismuth-214 activity, have more radium in the soil.

The radiometric signal explains more of the variance in the Cowra data set than the Mary River data, as judged from the $R^{2}$ values. This may be explained by less variability in the soil type at Cowra, as was observed qualitatively in the field. Although a relationship between soil radium and radon flux density is well supported within each of the data sets, the importance of other factors is also revealed. For the same equivalent specific activity of radium, Cowra fluxes are three times larger than at Mary River. In the context of our model, this may be a result of the two areas having different soil types, different soil moisture, or a combination of both.

\subsection{Modelled versus observed seasonal cycle}

Seasonal changes in soil moisture lead to seasonal changes in radon exhalation as very dry soil or very wet soil reduces flux density at the surface.

The Cataract data set, detailed in Table 1, is a year-long time series of radon measurements acquired by sampling seven nearby sites (within $400 \mathrm{~m}$ ) each fortnight. The temporal changes in radon-222 flux were not well correlated between these sites, though the sites were consistent in the sense that, for most measurements, the ordering of low to high flux remained constant.

Compared with radon-222, variations in radon-220 flux (not shown) were more strongly correlated across sites, perhaps reflecting the topsoil having a more uniform response to the combined effect of precipitation and evaporation than the subsoil.

As our model lacks the spatial resolution to capture the spatial variability between these sites, we focus on the temporal evolution of the mean flux across the seven sites, as shown in Fig. 5. The model, uncalibrated, overestimates 


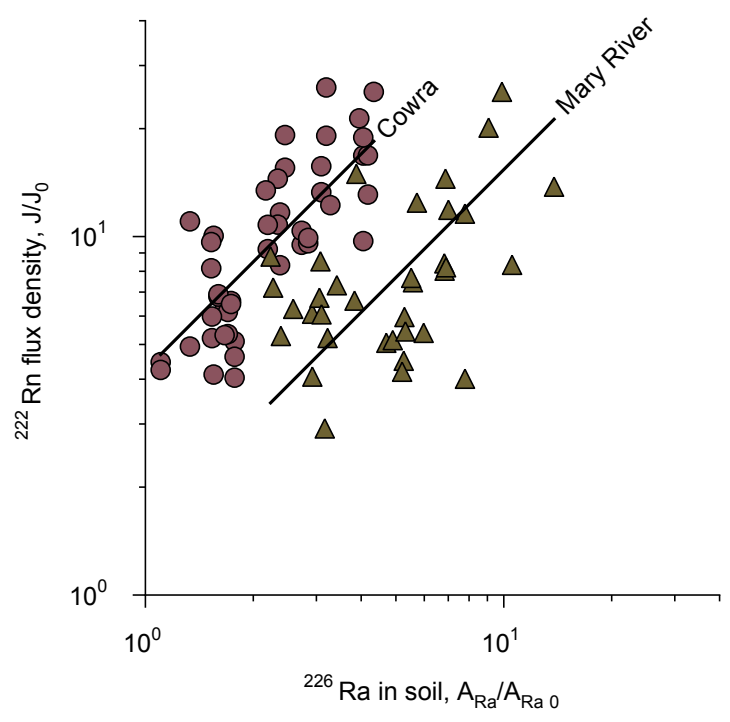

Fig. 4. Radon flux density versus radium-226 specific activity, as determined in the field from ground-based measurements of bismuth-214 gamma activity. The lines of best fit are $y=4.3 x$ ( $R^{2}=0.58$, circles mark measurements) for Cowra and $y=1.5 x$ ( $R^{2}=0.22$, triangles mark measurements) for Mary River. Radium activity and radon flux density are normalised by typical average values, $A_{\mathrm{Ra} 0}=30 \mathrm{~Bq} \mathrm{~kg}^{-1}$ and $J_{0}=22 \mathrm{mBq} \mathrm{m}^{-2} \mathrm{~s}^{-1}$.

radon flux density up until May and then follows observations reasonably well, correctly capturing the minimum in late September, which is a response to high rainfall in that month.

On the other hand, the flux density at this location changes little throughout the year and a constant would fit the observations just as well as the model. Combined with the low signal-to-noise ratio in the data, it appears that this location, at least for 1998, is not a strong test of the model's representation of temporal changes.

Some other, though limited, data exist to which we can compare the model. Whittlestone et al. (1998) attempted to quantify the seasonal variation of radon flux density in Tasmania by making measurements in February and then again in July 1996. Considering only the 9 sites were repeat measurements were made, the mean flux density in February, $26.3 \mathrm{mBq} \mathrm{m}^{-2} \mathrm{~s}^{-1}$, was larger than that in July, $16.2 \mathrm{mBq} \mathrm{m}^{-2} \mathrm{~s}^{-1}$, by a factor of 1.6. This is comparable to the seasonal variation in the model which was a factor of 2.4 for the same times when averaged across the whole of Tasmania.

Returning to the data listed in Table 1, the repeat measurements made at Cowra and Goulburn are another possible means to examine temporal variability. For each of these localities, measurements were made in summer and winter, so we can compute the ratio of summer-to-winter mean fluxes and obtain an estimate of the seasonal cycle, at least for the years in which measurements were made.

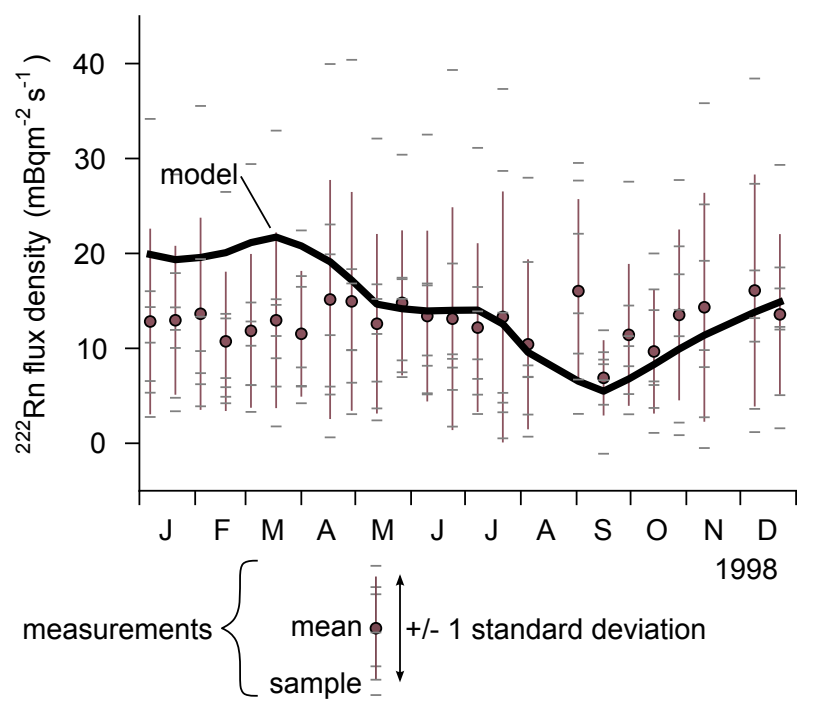

Fig. 5. Time series of measured and modelled radon flux density during 1998 from the Cataract data set. The average flux density over the entire year was measured to be $12.6 \mathrm{mBqm}^{-2} \mathrm{~s}^{-1}$, whereas the uncalibrated model was $14.5 \mathrm{mBq} \mathrm{m}^{-2} \mathrm{~s}^{-1}$.

We consider first the Cowra data. Although these are made during different seasons, it turns out that the soil moisture was similar in February and July 2008. This is reflected in the measured ratio of summer-to-winter radon flux, which was 0.88. In model output, summer and winter fluxes are also similar but the ratio is reversed; the modelled ratio of summer-to-winter radon flux is 1.30 .

In Goulburn, measurements were made in August 2006 and again in February 2008. The measured summer-towinter ratio was 2.54 compared with 1.10 from model output, considering only those points sampled twice. So, at this location and for these times, the model is underestimating the change in radon flux by a large margin.

The magnitude of the cycle is not particularly well constrained by these data and there is contradictory evidence about whether the model overestimates or underestimates the seasonal cycle. One complicating factor, which might be contributing to the discrepancy, is that some soil types show higher diffusion coefficients near $m=0.2$ than when dry (Papachristodoulou et al., 2007). This has the potential to drive an inverted seasonal cycle, when compared with the expression used in our model, Eq. (6), in which the diffusion coefficient decreases monotonically with increasing moisture.

Although they highlight some of the limitations of the model, these data nevertheless indicate that radon exhalation can change significantly on seasonal time scales, thereby indicating that temporal variability should be included in the model. 


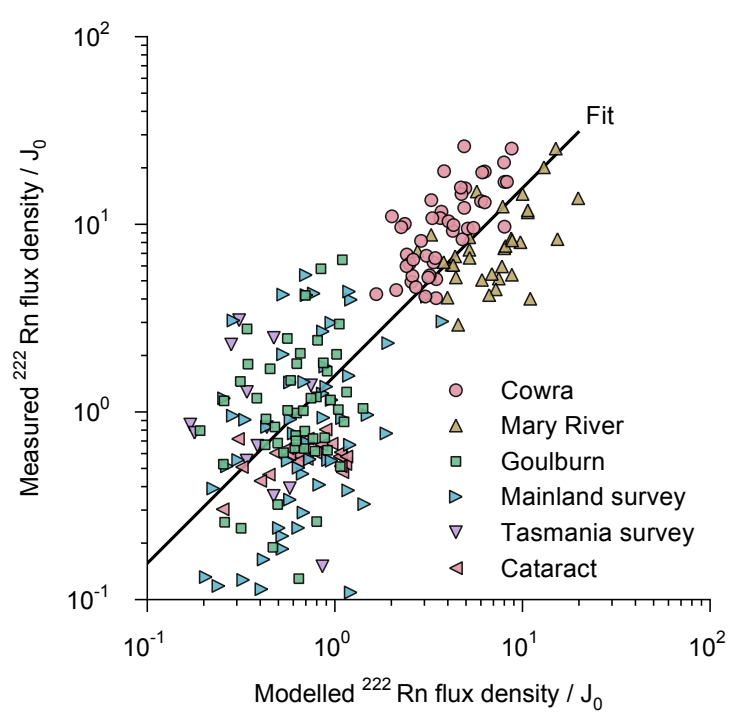

Fig. 6. Correlation between modelled and measured radon flux density, $J_{0}=22 \mathrm{mBqm}^{-2} \mathrm{~s}^{-1}$. The line of best fit is $y=1.6 x$ with $R^{2}=0.48$. Repeat measurements are grouped together: Cowra data are from Feb and Jul 2008; Mary River from September 2008; Goulburn from August 2006 and February 2008; Mainland from June 1986; Tasmanian from February and August 1996 and December 1997; and Cataract data from January-December 1998. The Cataract points shown are the average across all Cataract sites for each of the measurement days and are not included in the fit.

\subsection{Model calibration}

The model was calibrated, according to Eq. (12), from the flux data listed in Table 1 and the result is shown in Fig. 6.

Some minor data conditioning was performed prior to performing the fits. Points where either flux density or radium specific activity was $1 / 10$ th or less than the Australian average were excluded to prevent the poor signal-to-noise ratio of these points from contributing; for the flux chamber the chosen cut-off corresponds to a relative error of about $40 \%$. Cataract data were also excluded in the fit, as these 175 measurements were taken within a small area thus representing only a single soil type and a single pixel of radiometric data, so their raw inclusion would bias the final result. These points are shown in Fig. 6 for comparison; measurements here are on average lower than the calibrated model, but not outside the scatter of the other data.

Overall, we find that measured fluxes are larger than fluxes modelled with Eq. (7). The calibration factor is $c=1.56 \pm 0.14$, where the uncertainty estimate is the RMS deviation from $c$ of repeated line fits, each with one of the measurement data sets excluded. This results in a larger error estimate than that derived from the flux chamber measurement errors and is intended to take into account systematic differences between the data sets.

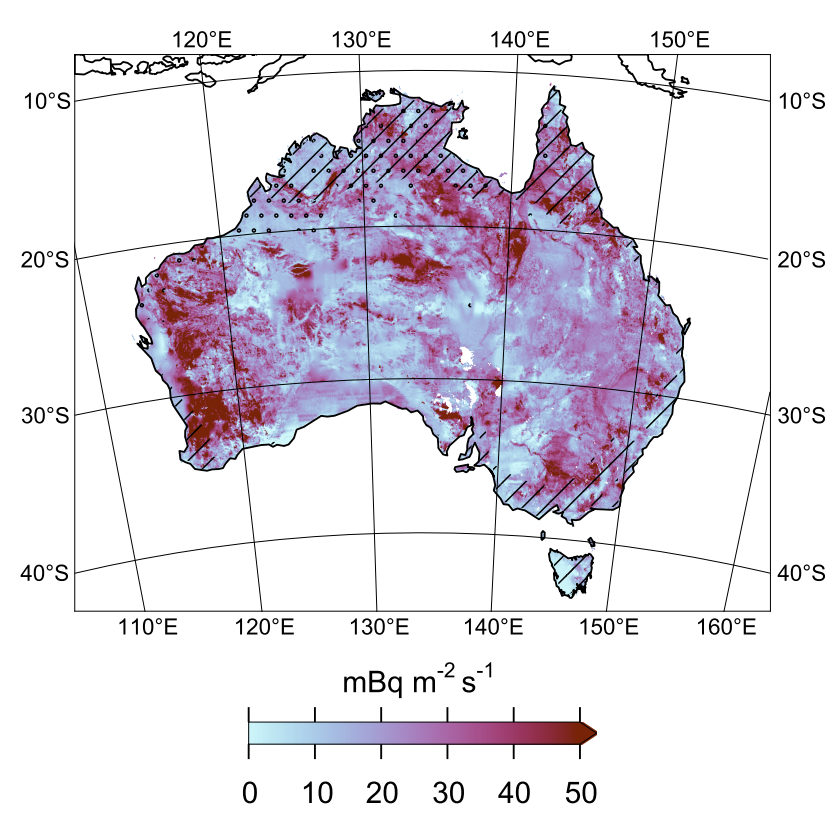

Fig. 7. Mean radon-222 flux density over the period July 1979-June 2010, the area-weighted mean is $23.4 \pm 2.0 \mathrm{mBqm}^{-2} \mathrm{~s}^{-1}$. The hatched region shows where the topsoil is wet enough to reduce radon flux by $25 \%$ from its maximum value for two or more months of the year and the stippled region shows where the topsoil is dry enough to reduce radon flux by $25 \%$ from its maximum value for two or more months of the year.

\subsection{Radon flux maps}

By computing Eq. (7) at each model grid-point and applying the calibration factor, $c$, we obtain monthly radon flux maps. Averaging over the period July 1979-June 2010 (inclusive) results in the mean radon flux map shown in Fig. 7 , which has a median value of $20.86 \mathrm{mBqm}^{-2} \mathrm{~s}^{-1}$. The areaweighted arithmetic mean flux over this 30 year period is $23.4 \pm 2.0 \mathrm{mBq} \mathrm{m}^{-2} \mathrm{~s}^{-1}$, with uncertainty arising from the uncertainty in $c$ but not including the uncertainty due to the accumulation chamber technique, which is about $10 \%$ as discussed in Sect. 2.1. This is consistent with an earlier estimate, $22 \mathrm{mBq} \mathrm{m}^{-2} \mathrm{~s}^{-1}$, from Schery et al. (1989) which was based on the mainland survey data of Table 1 .

Regions of high and low radon flux in Fig. 7 largely result from variations in soil radium, though moisture is also important in places. According to Fig. 1, radon flux can be inhibited by extremely dry conditions or wet conditions. In Fig. 7, it is apparent that the effect of low soil moisture is only present in a relatively small area. If soil moisture is to affect radon flux, it is more likely to be due to the soil being wet than dry. An example of this, visible in the mean flux, is the contrast between the east and west of Tasmania which is due to persistently dryer conditions towards the east.

On average, the modelled flux density approximates a lognormal distribution but with a greater proportion of small flux 


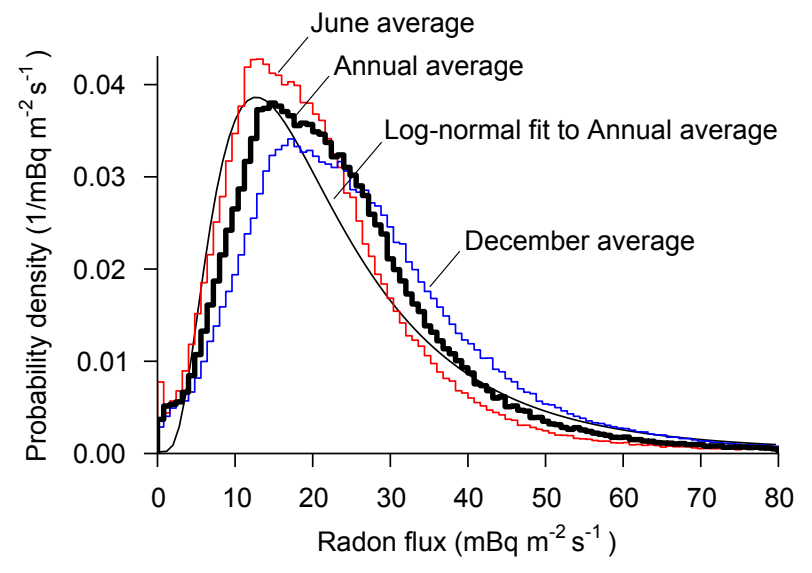

Fig. 8. Histograms of radon flux density maps. A theoretical distribution is fit to the July 1979-June 2010 mean flux by computing a log-normal distribution with the same mean and standard deviation of $\log J$, where $J$ is radon flux density, as the map.

values, as shown in Fig. 8. There is a large scale meridional variation whereby the mean flux density decreases sharply poleward of $35^{\circ} \mathrm{S}$ (Fig. 9). Although this is comparable to the northern hemisphere results of Conen and Robertson (2002), it is not necessarily representative of the entire southern hemisphere; the meridional gradient in our map, which begins on the southern tip of the mainland and extends across Tasmania, follows a dramatic decrease in zonallyintegrated land area.

As well as spatial variability, parts of Australia show large seasonal departures from the long-term mean, as shown in Fig. 10. As expected from the model formulation, the seasonal patterns of radon flux mainly follow moisture. Away from the interior, which has a weak seasonal cycle, changes of $\pm 10 \mathrm{mBq} \mathrm{m}^{-2} \mathrm{~s}^{-1}$, almost half of the annual mean, are common. Due to different seasonal rainfall patterns, the radon cycle in the south is out of phase with the north. In south-east Australia (defined here as east of $140^{\circ} \mathrm{E}$ and south of $30^{\circ} \mathrm{S}$ ) we find that the model predicts a significant seasonal cycle, as shown in Fig. 11, with a larger flux in summer.

\section{Discussion}

\subsection{Map limitations}

There are two main features of Fig. 6 that point to limitations in the model and data underlying the flux map: (1) flux density measurements are scattered about the line of fit; and (2) data from different measurement sets are biased relative to each other. We discuss each of these issues in turn.

Although flux density and radium activity measurements both rely on counting radioactive decay, and therefore become increasingly noisy at low levels, other uncertainties

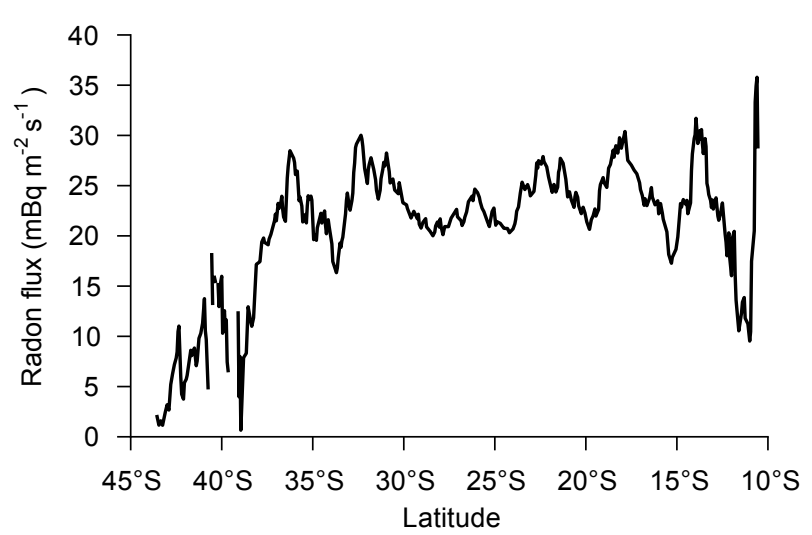

Fig. 9. Mean radon flux density versus latitude.

dominate the scatter in Fig. 6, particularly uncertainties in model inputs.

Soil radium is a central model input and, for the purpose of calibrating the model, was derived from gamma measurements which varied in quality between data sets. For Mary River and Cowra, ground-based measurements were made in the field using portable gamma spectrometers, thereby sampling an area of radius $\sim 1 \mathrm{~m}$ and depth $25 \mathrm{~cm}$, or over $100 \mathrm{~kg}$ of soil (IAEA, 2003); for Tasmania soil was collected and $250 \mathrm{~g}$ samples measured in the lab using a germanium gamma spectrometer; whereas the other data sets used values extracted from aerial survey data (Radmap), with an effective resolution of $500 \mathrm{~m}$ which is the maximum spacing between flight lines. Out of these measurements, the portable gamma spectrometer samples a volume of soil which corresponds best with the radon source region, and this contributes to Mary River and Cowra data having less scatter than other data sets.

In addition to sampling a larger region than the flux chamber measurements, the extraction of the correct pixel of radiometric data is not guaranteed due to the uncertainty in measurement locations. This was not a concern for the Goulburn data set, where locations were measured using standard GPS with an uncertainty of about $10 \mathrm{~m}$, but GPS was unavailable for the Tasmanian and Mainland survey data where locations are known to about $1 \mathrm{~km}$ accuracy.

Also a factor is the uncertainty due to soil types, which are expected to be poorly characterised, and the derived soil properties which, warn McKenzie et al. (2000), are but an "interim measure". This contributes to offsets between the different data sets and also to increased scatter in the largearea surveys which sample multiple soil types.

For the Cowra and Mary River data, which were collected over small enough areas to sample relatively consistent soil types and which also included ground-based radiometric data, the dominant source of scatter may well be a result of assuming that point measurements of flux density are representative of the monthly mean. Based on observed short-term 

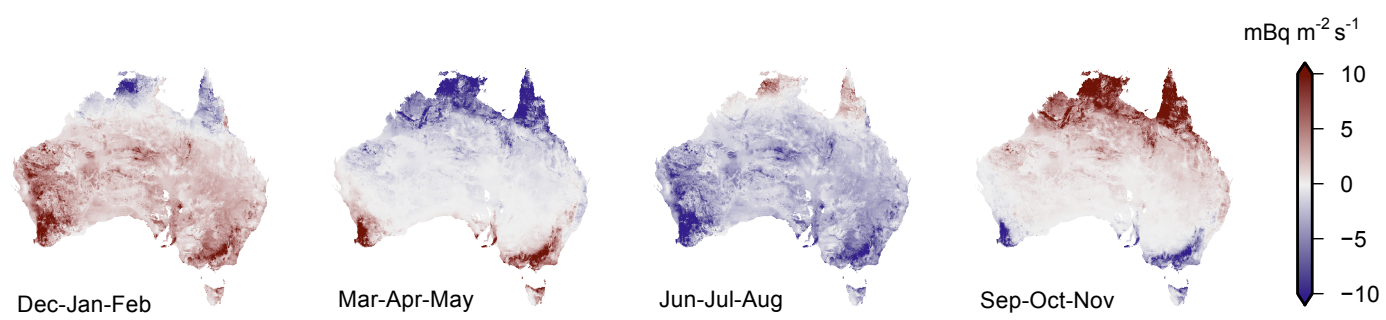

Fig. 10. Seasonal mean radon flux anomalies for July 1979-June 2010.

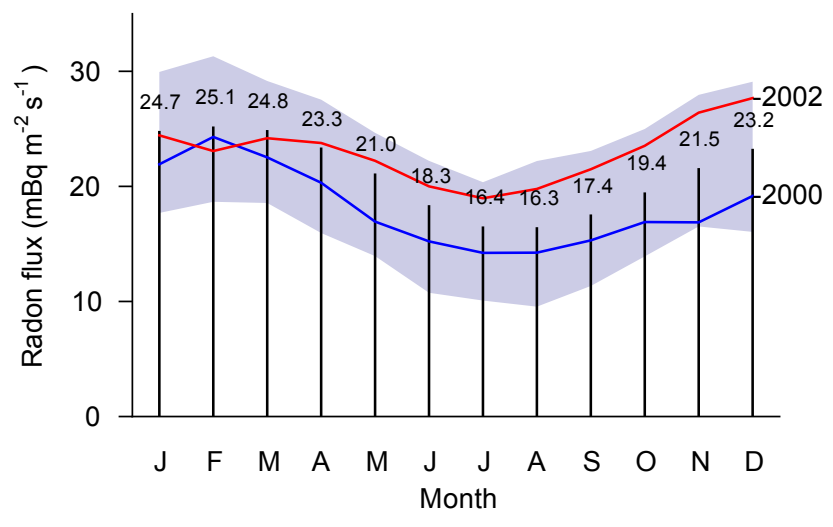

Fig. 11. Radon flux seasonal cycle for the area south of $30^{\circ} \mathrm{S}$ and east of $140^{\circ} \mathrm{E}$, July $1979-$ June 2010 . Labelled bars show the mean, the shaded region shows the range and examples of two years are also shown, 2002 (a relatively dry year) and 2000 (a relatively wet year).

fluctuations (Holford et al., 1993), this is estimated to be a random error contributing about a factor of two to the measurement uncertainty. This is large enough to be a significant contributor to the scatter across the entire data set.

To better understand the biases present in data from the individual campaigns, we consider the Cowra and Mary River data in more detail. Although modelled fluxes per unit soil radium are similar, measured fluxes differ substantially, which may indicate that the model is failing to capture some important difference between the locations. In fact, if the model is tuned to match Cowra data it is 2.4 times too high at Mary River. This is only slightly better than the factor of 2.9 difference, which is observed when applying a direct correlation with radiometrics (Fig. 4). In contrast, Fig. 12 shows a stronger correlation between radon-220 and radiometrics and a smaller systematic difference between the two sites.

Both locations were visited during times when topsoil moisture was consistently lower than $20 \%$, both according to AWAP and field measurements in the top $12 \mathrm{~cm}$, and according to Fig. 1 a factor of two difference would require the soil moisture at Mary River to approach $60 \%$. Based on this, the effect of moisture on diffusive transport within the pore space is an unlikely cause of the inconsistency and other soil

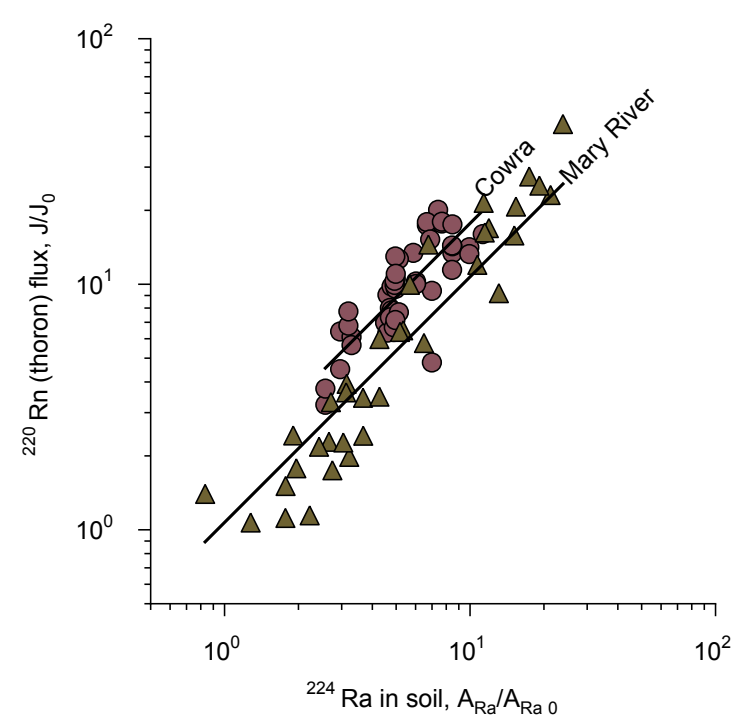

Fig. 12. Observed correlation between radium-224 specific activity, as determined from field radiometrics using the thorium channel, and radon-220 (thoron) flux. The lines of best fit are $y=1.8 x\left(R^{2}=0.55\right.$, circles mark measurements) for Cowra and $y=1.1 x\left(R^{2}=0.79\right.$, triangles mark measurements $)$ for Mary River. Radium-224 activity is normalised by $A_{\mathrm{Ra} 0}=30 \mathrm{~Bq} \mathrm{~kg}^{-1}$ and flux by $J_{0}=1.7 \mathrm{~Bq} \mathrm{~m}^{2} \mathrm{~s}^{-1}$.

properties are more likely to be the cause. For instance, the emanation fraction, $f$, is spatially resolved in the model but is estimated from a cascade of empirical correlations, as outlined in Sects. 2.2 and 2.3, with a resulting large uncertainty.

Problems with uncertainties in the emanation fraction are exacerbated by a feedback affecting radiometric measurements, from which we estimate radium concentration. In this method, soil radium is determined by counting gamma rays emitted by bismuth-214, a decay product of radon-222, and by assuming that the decay chain is in secular equilibrium, i.e. the activity concentration of radium-226 is assumed to equal that of radon-222 and bismuth-214. Equilibrium in soil is unlikely, however, as a fraction of radon escapes from the soil surface thus bismuth-214 activity will be lower than radium-226 activity, which means that the apparent radium content of soil will be lower than the true value (Dickson and Scott, 1997; Minty and Wilford, 2004). 
This would be a non-issue if the error remained constant, since we account for constant systematic errors by introducing a calibration factor in Eq. (11), but in fact the magnitude of the error is a function of radon flux. Consider two sites that have identical radium concentrations, but one with a higher radon flux: at the low-flux site, the apparent radium concentration will be higher, which means that the model will predict a high radon flux here and a low flux at the other site. This is exactly the opposite to the desired behaviour, due not to a limitation of the model but to a systematic dependence of the input data on the quantity we are trying to predict.

To estimate the magnitude of this effect consider, for a moment, a simplified version of the flux model with dry, homogeneous, and very deep soil. Based on Eq. (4) the modelled steady state radon flux to the atmosphere can be written as

$$
J_{m}=c f A_{\mathrm{Ra}}^{\prime} K
$$

where $c$ is the calibration factor, $0 \leq f<1$ is the emanation fraction, $A_{\mathrm{Ra}}^{\prime}$ is the apparent radium content of the soil, according to radiometrics, and $K$ is the rest of the terms in Eq. (4) lumped together. The calibration factor is chosen so that, despite any other problems the model might have, $J_{m}$ matches observations on average.

If we assume that the true radium content of the soil, $A_{\mathrm{Ra}}$, is equal to that derived from radiometrics then $A_{\mathrm{Ra}}^{\prime}=A_{\mathrm{Ra}}$. Substituting into Eq. (13) and then differentiating with respect to $f$,

$$
\begin{aligned}
\frac{\partial J_{m}}{\partial f} & =c A_{\mathrm{Ra}} K \\
& =J_{m} / f
\end{aligned}
$$

Or, with $\delta J_{m}$ and $\delta f$ representing small changes,

$$
\frac{\delta J_{m}}{J_{m}}=\frac{\delta f}{f},
$$

which is to say that we expect a fractional change in $f$ to cause $J_{m}$ to change by the same fraction.

Contrary to the above assumption, $A_{\mathrm{Ra}}^{\prime}$ is not equal to the true radium concentration. The counts recorded by a ground level gamma detector are (Grasty, 1997)

$$
\frac{N}{N_{0}}=1-\mu_{g} f l_{d} \log \left(1+\frac{1}{\mu_{g} l_{d}}\right)
$$

where $N_{0}$ is the number of counts that would be observed without radon movement, $\mu_{g}$ is the gamma-ray attenuation coefficient and $l_{d} \equiv \sqrt{D_{e} / \lambda}$ is the diffusion length. The inferred radium specific activity, $A_{\mathrm{Ra}}^{\prime}$, is proportional to the number of counts, so from Eq. (15) we can write

$A_{\mathrm{Ra}}^{\prime}=\left(1-c_{J} f\right) A_{\mathrm{Ra}}$

where $A_{\mathrm{Ra}}$ is the true radium specific activity and $c_{J}=$ $\mu_{g} l_{d} \log \left[1+1 /\left(\mu_{g} l_{d}\right)\right]$ is the radon flux correction. For a typical dry soil, $\mu_{g}=7.23 \mathrm{~m}^{-1}$, and $l_{d}=1.1 \mathrm{~m}$ so $c_{J}=$ 0.942 .

The simplified model, Eq. (13), can be rewritten to take Eq. (16) into account so that

$J_{m}=c f\left(1-c_{J} f\right) A_{\mathrm{Ra}} K$

which also requires $c$ to take a new value to maintain the on-average fit to observations. If we again differentiate with respect to $f$ and transform into a form similar to Eq. (14), we find

$\frac{\delta J_{m}}{J_{m}}=\frac{\delta f}{f} \frac{1-2 c_{J} f}{1-c_{J} f}$.

For a soil with $f=0.35$, which is relatively high but corresponds to silt with $m=0.1$ (Zhuo et al., 2008), a change of $10 \%$ in $f$ leads to a change in flux of $5 \%$. For this soil type, therefore, the effect of changing $f$ is underestimated by a factor of two, but the importance of this effect decreases with $f$.

A similar argument can be followed to determine the effect of changes in the diffusion length but, from Eq. (15), the apparent radium concentration tends towards an asymptote for $l_{d} \gtrsim 0.3 \mathrm{~m}$. Shorter diffusion lengths than this are expected only in unusual situations, such as when soil approaches saturation, so the effect due to changing emanation fraction dominates.

For the thorium channel, which detects gamma rays emitted by thallium-208, $\lambda / D \ll 1$ and $N \simeq N_{0}$ regardless of $f$. As a result, radium-224 measurements are unaffected by changes in $f$. Comparing Fig. 4 and Fig. 12, radon220 fluxes match radiometrics more closely across both locations and radon-222 fluxes indeed differ by around twice as much as radon-220. Emanation coefficients for radon220 and radon-222 can not be assumed to be similar, though (Greeman and Rose, 1996), so the degree to which this effect alone is responsible for the difference between Cowra and Mary River data can not be ascertained without further investigation.

In general, radon-222 transport is more complicated than radon-220 because of the longer diffusion length and the potential for soil properties to change with depth, which provides an alternative explanation for the difference between Figs. 4 and 12. Regardless of the details of this specific case, the implication is that the combination of input data from field radiometrics with our model of radon flux leads to a systematic underestimate of the model's response to changes in $f$. As a result, the overall spatial variability may be underestimated to some degree in the final map, but only to the extent that spatial variability is controlled by the emanation fraction, $f$. 


\subsection{Future work}

The Australian region has a sparse coverage of radon flux density measurements, so there are opportunities to improve the map by gathering more data. As the map calibration is based entirely on point flux measurements, the addition of different types of radon flux density measurements would be useful both to test and improve the map. In particular, long time series in areas of strong seasonal variability or an independent estimate of the integrated radon flux over an area would improve the map.

Enhancements to the moisture or soil parameter data would likely improve the accuracy of the map and would be simple to incorporate into future revisions.

Finally, a similar map could be produced with modest effort for radon-220, although this would require a data set of surface soil moisture with temporal resolution significantly better than one month.

\subsection{Implications for atmospheric studies}

For studies based on the applications of atmospheric radon, the value of using the present map instead of a constant-flux source function depends on whether or not it would significantly change atmospheric radon concentrations to do so. In either real-world observations or models, this will be the case whenever a measurement footprint covers an area whose radon flux differs from the national mean.

Cases of this are easy to envisage, for example: (1) the nocturnal peak radon concentration in a stable nocturnal boundary layer is directly related to the local flux; (2) seasonal variations away from the dry interior are important over large enough areas to drive seasonal variation in daytime radon concentrations; and (3) the mean flux density variability is spatially coherent over sufficiently large scales for atmospheric radon to depend on wind direction at many sites, even after the integrating effect of atmospheric mixing. The generality of these cases demonstrates the possibility of significant implications for the full range of atmospheric radon studies discussed in the introduction.

\section{Conclusions}

Our main result, the first detailed radon flux map produced for Australia, shows that the usual assumption of constant radon flux is unrealistic, whether the assumption be applied spatially or temporally. The mean flux density, $23.4 \pm 2.0 \mathrm{mBq} \mathrm{m}^{-2} \mathrm{~s}^{-1}$, however, is consistent with a previous estimate based on a subset of the data used in this study (Schery et al., 1989).

The spatial variability in our map may be an underestimate of the true variability, as a result of using gamma surveys to estimate soil radium content. We show that this is because the gamma survey data is sensitive to changes in the emanation coefficient, in the opposite sense to radon flux, which makes the combined model-data system respond weakly to changes in the emanation coefficient. If this parameter controls at least some of the spatial variability in the true radon flux density, the spatial variability likewise will be underestimated to some degree.

Radon flux density varies on seasonal timescales, and a factor of two difference between summer and winter fluxes is predicted by the model over wide areas. This is comparable to direct measurements within Australia and with previous studies in other parts of the world. Nevertheless, the present data set does not constrain the seasonal cycle well and seasonal variability remains to be investigated further in the future.

The map presented here covers a similar spatial extent to the recently published European map (Szegvary et al., 2009), and cross-comparison of the measurement instruments means that the two maps are referenced to a common datum, thus allowing them to be meaningfully compared.

The application of a monthly radon flux map, such as that produced in our study, will enhance the accuracy and applicability of atmospheric studies using radon as a tracer, including simulations of radon in global and regional models.

Digital versions of the map are available from the authors.

Acknowledgements. We gratefully acknowledge the following contributors: Stephen Schery for making his radon flux measurements available; Brian Minty for supplying gamma-ray aerial survey data (copyright Geoscience Australia, 2003) and providing advice on its interpretation; Stewart Whittlestone, Michael Hyde and Melanie Lautenschläger who performed some of the flux measurements; The Australian Water Availability Project, in particular Peter Briggs, for supplying soil moisture data (copyright CSIRO, 2008 and used under the terms of the Creative Commons Attribution-Share Alike License version 3.0); Alastair Williams and Scott Chambers for reviewing an early draft of the manuscript; Steve Schery, Weihai Zhuo and two anonymous referees for commenting on the Discussion Paper; and property owners who allowed us access to their land.

Edited by: T. Butler

\section{References}

Antonopoulos-Domis, M., Xanthos, S., Clouvas, A., and Alifrangis, D.: Experimental and theoretical study of radon distribution in soil, Health Phys., 97, 322-331, doi:10.1097/HP. 0b013e3181adc157, 2009.

Biraud, S., Ciais, P., Ramonet, M., Simmonds, P., Kazan, V., Monfray, P., O’Doherty, S., Spain, T. G., and Jennings, S. G.: European greenhouse gas emissions estimated from continuous atmospheric measurements and radon 222 at Mace Head, Ireland, J. Geophys. Res., 105(D1), 1351-1366, doi:10.1029/ 1999JD900821, 2000.

Bureau of Rural Sciences: Australian Natural Resources Data Library, online available at: http://adl.brs.gov.au/anrdl/, last access: 28 October 2009. 
Conen, F. and Robertson, L.: Latitudinal distribution of radon222 flux from continents, Tellus B, 54, 127-133, doi:10.1034/ j.1600-0889.2002.00365.x, 2002.

Dickson, B. L. and Scott, K. M.: Interpretation of aerial gamma-ray surveys - adding the geochemical factors, AGSO J. Aust. Geol. Geophys., 17, 187-200, 1997.

Goto, M., Moriizumi, J., Yamazawa, H., Iida, T., and Zhuo, W.: Estimation of global radon exhalation rate distribution, in: The Natural Radiation Environment - 8th International Symposium, edited by: Paschoa, A. S., 169-172, Americal Institute of Physics, 2008.

Grasty, R. L.: Radon emanation and soil moisture effects on airborne gamma-ray measurements, Geophysics, 62, 1379-1385, doi:10.1190/1.1444242, 1997.

Greeman, D. J. and Rose, A. W.: Factors controlling the emanation of radon and thoron in soils of the eastern USA, Chem. Geol., 129, 1-14, doi:10.1016/0009-2541(95)00128-X, 1996.

Gupta, M., Douglass, A. R., Kawa, S., and Pawson, S.: Use of radon for evaluation of atmospheric transport models: sensitivity to emissions, Tellus B, 56, 404-412, doi:10.1111/j.1600-0889. 2004.00124.x, 2004.

Hirsch, A. I.: On using radon-222 and $\mathrm{CO}_{2}$ to calculate regional-scale $\mathrm{CO}_{2}$ fluxes, Atmos. Chem. Phys., 7, 3737-3747, doi:10.5194/acp-7-3737-2007, 2007.

Holford, D. J., Schery, S. D., Wilson, J. L., and Phillips, F. M.: Modeling Radon Transport in Dry, Cracked Soil, J. Geophys. Res., 98, 567-580, doi:10.1029/92JB01845, 1993.

Hutter, A. R. and Knutson, E. O.: An international intercomparison of soil gas radon and radon exhalation measurements, Health Phys., 74, 108-114, doi:10.1097/00004032-199801000-00014, 1998.

International Atomic Energy Agency: Guidelines for radioelement mapping using gamma ray spectrometry data, IAEA-TECDOC1363, IAEA, Vienna, 2003.

Jacob, D., Prather, M., Rasch, P., Shia, R., Balkanski, Y., Beagley, S., Bergmann, D., Blackshear, W., Brown, M., Chiba, M., et al.: Evaluation and intercomparison of global atmospheric transport models using ${ }^{222} \mathrm{Rn}$ and other short-lived tracers, J. Geophys. Res, 102, 5953-5970, doi:10.1029/96JD02955, 1997.

Jones, D. A., Wang, W., and Fawcett, R: Climate data for the Australian Water Availability Project Final Milestone Report, National Climate Centre, Australian Bureau of Meteorology, 36 pp., 2007.

Lehmann, B. E., Lehmann, M., Neftel, A., Gut, A., and Tarakanov, S. V.: Radon-220 calibration of near-surface turbulent gas transport, Geophys. Res. Lett., 26, 607-610, 1999.

Markkanen, M. and Arvela, H.: Radon Emanation from Soils, Radiat. Prot. Dosim., 45, 269-272, 1992.

Mayya, Y. S.: Theory of radon exhalation into accumulators placed at the soil-atmosphere interface, Radiat Prot Dosimetry, 111, 305-318, doi:10.1093/rpd/nch346, 2004.

McKenzie, N. and Hook, J.: Interpretations of the Atlas of Australian Soils, CSIRO Division of Soils Technical Report, 94, 1992.

McKenzie, N., Land, C., and Water: Estimation of Soil Properties Using the Atlas of Australian Soils, Tech. Rep. 11/00, CSIRO, http://www.clw.csiro.au/publications/technical2000/ (last access: October 2009), 2000.

Minty, B.: Fundamentals of airborne gamma-ray spectrometry,
AGSO J. Aust. Geol. Geophys., 17, 39-50, 1997.

Minty, B.: Automatic merging of gridded airborne gamma-ray spectrometric surveys, Explor. Geophys., 31, 47-51, doi:10.1071/ EG00047, 2000.

Minty, B. and Wilford, J.: Radon effects in ground gamma-ray spectrometric surveys, Explor. Geophys., 35, 312-318, doi:10.1071/ EG04312, 2004.

Minty, B. R. S., Franklin, R., Milligan, P. R., Richardson, L. M., and Wilford, J.: The Radiometric Map of Australia, in: 20th International Geophysical Conference and Exhibition, Australian Society of Exploration Geophysicists, Adelaide, 2009.

Nazaroff, W.: Radon transport from soil to air, Rev. Geophys., 30, 137-160, doi:10.1029/92RG00055, 1992.

Northcote, K., Beckmann, G., Bettenay, E., Churchward, H., Dijk, D. V., Dimmock, G., Hubble, G., Isbell, R., McArthur, W., and Murtha, G.: Atlas of Australian Soils, Sheets 1 to 10, with explanatory data, 1960.

Papachristodoulou C, Ioannides K, Spathis S.: The effect of moisture content on radon diffusion through soil: assessment in laboratory and field experiments, Health Phys., 92(3), 257-264, doi: 10.1097/01.HP.0000248147.46038.bc, 2007.

Raupach, M. R., Briggs, P. R., Haverd, V., King, E. A., Paget, M., and Trudinger, C. M.: Australian Water Availability Project, online available at: http://www.csiro.au/awap/, 2008.

Raupach, M. R., Briggs, P. R., Haverd, V., King, E. A., Paget, M., and Trudinger, C. M.: Australian Water Availability Project (AWAP): CSIRO Marine and Atmospheric Research Component: Final Report for Phase 3, CAWCR technical report, CSIRO, 2009.

Rogers, V. C. and Nielson, K. K.: Correlations for predicting air permeabilities and ${ }^{222} \mathrm{Rn}$ diffusion coefficients of soils, Health Phys., 61, 225-230, doi:10.1097/00004032-199108000-00006, 1991.

Sakoda, A., Ishimori, Y., Hanamoto, K., Kataoka, T., Kawabe, A., and Yamaoka, K.: Experimental and modeling studies of grain size and moisture content effects on radon emanation, Radiat. Meas., 45, 204-210, doi:10.1016/j.radmeas.2010.01.010, 2010.

Sasaki, T., Gunji, Y., and Okuda, T.: Mathematical modeling of Radon emanation, J. Nucl. Sci. Tech., 41, 142-151, doi:10.3327/ jnst.41.142, 2004.

Schery, S., Gaeddert, D., and Wilkening, M.: Factors affecting exhalation of radon from a gravelly sandy loam, J. Geophys. Res., 89, 7299-7309, doi:10.1029/JD089iD05p07299, 1984.

Schery, S., Whittlestone, S., Hart, K., and Hill, S.: The flux of radon and thoron from Australian soils, J. Geophys. Res, 94, 85678576, doi:10.1029/JD094iD06p08567, 1989.

Schery, S. D. and Huang, S.: An estimate of the global distribution of radon emissions from the ocean, Geophys. Res. Lett., 31, L19104, doi:10.1029/2004GL021051, 2004.

Schery, S. D. and Wasiolek, M. A.: Radon and Thoron in the Human Environment, chap. Modeling Radon Flux from the Earth's Surface, 207-217, World Scientific Publishing, World Scientific Publishing, Singapore, 1998.

Szegvary, T., Leuenberger, M. C., and Conen, F.: Predicting terrestrial ${ }^{222} \mathrm{Rn}$ flux using gamma dose rate as a proxy, Atmos. Chem. Phys., 7, 2789-2795, doi:10.5194/acp-7-2789-2007, 2007.

Szegvary, T., Conen, F., and Ciais, P.: European ${ }^{222}$ Rn inventory for applied atmospheric studies, Atmos. Environ., 43, 1536-1539, doi:10.1016/j.atmosenv.2008.11.025, 2009. 
United States Department of Agriculture: Field book for describing and sampling soils, Version 2.0., Natural Resources Conservation Service, National Soil Survey Center, Lincoln, NE, available online at: http://soils.usda.gov/technical/fieldbook/ (last access: October 2008), 2002.

Watson, D.: The natural neighbor series manuals and source codes, Comput. Geosci., 25, 463-466, doi:10.1016/S0098-3004(98) 00150-2, 1999.

Werczynski, S., Conen, F., Zahorowski, W., and Chambers, S.: Comparison of University of Basel and ANSTO emanometers, Tech. rep., ANSTO, in preparation, 2010.

Whittlestone, S., Zahorowski, W., and Schery, S.: Radon flux variability with season and location in Tasmania, Australia, J. Radioanal. Nucl. Chem., 236, 213-217, doi:10.1007/BF02386345, 1998.

Williams, A., Chambers, S., Zahorowski, W., Crawford, J., Matsumoto, K., and Uematsu, M.: Estimating the Asian radon flux density and its latitudinal gradient in winter using ground-based radon observations at Sado Island, Tellus B, 61, 732-746, doi: 10.1111/j.1600-0889.2009.00438.x, 2009.
Zahorowski, W. and Whittlestone, S.: A Fast Portable Emanometer for Field Measurement of Radon and Thoron Flux, Radiat. Protect. Dosim., 67, 109-120, 1996.

Zahorowski, W., Chambers, S., and Henderson-Sellers, A.: Ground based radon-222 observations and their application to atmospheric studies, J. Environ. Radioact., 76, 3-33, doi:10.1016/j. jenvrad.2004.03.033, 2004.

Zhang, K., Wan, H., Zhang, M., and Wang, B.: Evaluation of the atmospheric transport in a GCM using radon measurements: sensitivity to cumulus convection parameterization, Atmos. Chem. Phys., 8, 2811-2832, doi:10.5194/acp-8-2811-2008, 2008.

Zhuo, W., Iida, T., and Furukawa, M.: Modeling Radon Flux Density from the Earth's Surface, J. Nucl. Sci. Tech., 43, 479-482, doi:10.3327/jnst.43.479, 2006.

Zhuo, W., Guo, Q., Chen, B., and Cheng, G.: Estimating the amount and distribution of radon flux density from the soil surface in China, J. Environ. Radioact., 99, 1143-1148, doi: 10.1016/j.jenvrad.2008.01.011, 2008. 